\title{
METHODS FOR OPTIMIZATION OF SEA WATERWAY SYSTEMS AND THEIR APPLICATION
}

Stanisław Gucma, Prof.

Wojciech Ślączka, Assoc. Prof.

Maritime University of Szczecin, Poland

\section{ABSTRACT}

This paper presents developed optimization methods for sea waterway systems. Objective function of optimization of sea waterway systems have been formulated and its detail form for fairways has been determined. Three probabilistic methods for determining safe bed-breadth of fairway are described. Limitations of the presented methods are also discussed. The developed optimization methods for sea waterway systems have been applied to determine parameters of a modernized fairway between Świnoujście and Szczecin as well as its navigation systems.

Keywords: Optimization of sea waterway systems; sea traffic engineering; probabilistic methods of determination safe breadth of fairways.

\section{INTRODUCTION}

System of sea waterways formulated in terms of sea traffic engineering consists of several seperated segments (n). Each of them consists of three basic elements [1]:

- waterway subsystem,

- $\quad$ ship position determination subsystem (navigation subsystem),

- $\quad$ ship traffic control subsystem.

The elements mutually iteract and significantly influence features of the whole system.

In practice all the sea waterway segments are often subjected to the same traffic control subsystem. On this assumption a sea waterway system can be reduced to two basic elements only:

- waterway subsystem,

- navigation subsystem.

System of sea waterways is defined by parameters of its elements ( subsystems). The two elements of sea waterway system at its particular segments are function of conditions for safe operation of ships. Therefore a system of i-th segment of sea waterway can be described by the following matrix expression:

$$
\left[\begin{array}{c}
\mathbf{A}_{\mathrm{i}} \\
\mathbf{N}_{\text {in }}
\end{array}\right]=f\left(\mathbf{W}_{\mathbf{i}}\right)
$$

In the above given formula the following matrix description was applied :

- for waterway subsystem :

$$
\mathbf{A}_{\mathbf{i}}=\left[\begin{array}{l}
t_{i} \\
l_{i} \\
D_{i} \\
h_{i}
\end{array}\right]
$$

where:

$t_{i}$ - type of $i$-th segment of waterway;

$l_{i}$ - length of $i$-th segment of waterway;

$\mathrm{D}_{\mathrm{i}}$ - breadth of accessible navigation area of $\mathrm{i}$-th segment of waterway;

$h_{i}$ - minimum depth of $i$-th segment of waterway;.

for navigation subsystem:

$$
\mathbf{N}_{\text {in }}=\left[\begin{array}{c}
d_{i n} \\
m_{i n} \\
n_{i n}
\end{array}\right]
$$

where:

$\mathrm{d}_{\text {in }}$ - accuracy of $\mathrm{n}$-th navigation system at $\mathrm{i}$-th segment of waterway (standard deviation);

$\mathrm{m}_{\mathrm{in}}$ - accessibility of $\mathrm{n}$-th navigation system at $\mathrm{i}$-th segment of waterway (depending on day-time and visibility);

$\mathrm{n}_{\mathrm{in}}$ - reliability of $\mathrm{n}$-th navigation system at $\mathrm{i}$-th segment of waterway ( technical reliability);

A state vector of conditions for safe operation of ships at i-th segment of a considered waterway can be presented as follows [1]:

$$
\mathbf{W}_{\mathbf{i}}=\left[t_{y p}, L_{c}, B, T, V_{i}, C_{i}, \mathbf{H}_{\mathbf{i}}\right]
$$

where:

$\mathrm{t}_{\mathrm{yp}}$ - type of , a maximum ship";

$\mathrm{L}_{\mathrm{c}}$ - length of , a maximum ship";

B - breadth of , a maximum ship";

$\mathrm{T}$ - draught of , a maximum ship”;

$\mathrm{V}_{\mathrm{i}}$ - permissible speed of „ a maximum ship” over $\mathrm{i}$-th segment of waterway; 


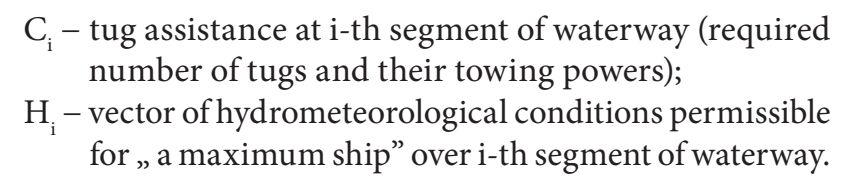

\section{OPTIMIZATION OF SEA WATERWAY SYSTEM}

The optimization of sea waterway system is carried out at determination of parameters of basic elements of a system under construction or re-construction (waterway subsystem, navigation subsystem). Parameters of the sea waterway system elements are function of designed (assumed). conditions of ship's safe operation (vector of state of ship's safe operation).

In issues of optimizing the parameters of sea waterway systems, an objective function is cost of construction (modernization) of waterway system elements and operational cost of its subsystems. On the assumptions, the objective function can be described as follows [5]:

$$
Z=(A 1+A 2+N 1+N 2+S) \rightarrow \min
$$

where:

$$
\begin{aligned}
& A 1=f_{1}\left(\mathbf{D}_{\mathbf{i}}, h_{x y}\right), \text { wherein }(x, y) \in \mathbf{X} \mathbf{1} \times \mathbf{Y} \mathbf{1}, \\
& A 2=f_{2}\left(\mathbf{D}_{\mathbf{i}}, h_{x y}\right), \\
& N 1=f_{3}\left(\mathbf{D}_{\mathbf{i}}, h_{x y}\right), \\
& N 2=f_{4}\left(\mathbf{D}_{\mathbf{i}}\right), \\
& S=f_{5}\left(\mathbf{D}_{\mathbf{i}}\right),
\end{aligned}
$$

i.e.:

$$
Z=F\left(\mathbf{D}_{\mathbf{i}}, h_{x y}\right) \rightarrow \min
$$

under constraints:

$$
\left.\begin{array}{c}
\mathbf{d}_{\mathbf{i}}(1-\alpha) \subset \mathbf{D}_{\mathbf{i}} \\
\bigwedge_{\mathrm{p}(\mathrm{x}, \mathrm{y}) \in \mathbf{D}_{\mathbf{i}}} h_{x y}(t) \geq T_{x y}(t)+\Delta_{x y}(t)
\end{array}\right\}
$$

where:

$\mathrm{D}_{\mathrm{i}}$ - accessible navigation water area complying with safe depth condition at $\mathrm{i}$-th segment of waterway;

$d_{i}(1-\alpha)$ - safe maneouvring area at $i$-th segment of waterway for a „maximum ship” maneouvring in set navigation conditions, determined on the confidence level of $1-\alpha$;

$\mathrm{Z}$ - cost of construction and operation of a waterway system;

A1 - cost of construction ( re-construction ) of a waterway;

A2 - cost of operation of a waterway;

$\mathrm{N} 1$ - cost of construction of a ship position determination subsystem (navigation systems);

N2 - cost of operation of navigation systems;

$\mathrm{S}$ - ship operation cost connected with passing a considered waterway ( pilotage, tug assistance etc );

$\mathrm{h}_{\mathrm{xy}}$ - water area depth in the point $\mathrm{x}, \mathrm{y}$;
$\mathrm{T}_{\mathrm{xy}}$ - ship draught in the point $\mathrm{x}, \mathrm{y}$;

$\Delta_{\mathrm{xy}}-$ underkeel clearance in the point $\mathrm{x}, \mathrm{y}$.

In the case of sea waterways of constant depth $\left(\mathrm{h}_{\mathrm{xy}}=\right.$ const) the objective function can be expressed as follows:

$$
Z=F\left(\mathbf{D}_{\mathbf{i}}\right)
$$

under constraints:

$$
D_{j} \geq d_{j}(1-\alpha)
$$

where:

$\mathrm{D}_{j}$ - accessible bed-breadth of a fairway in $\mathrm{j}$-th point of fairway axis;

$d_{j}(1-\alpha)$ - safe breadth of a fairway on bottom level of a "maximum ship” maneouvring in set navigation conditions in $j$-th point of fairway axis, determined on the confidence level of 1- $\alpha$.

\section{PROBABILISTIC METHODS FOR DETERMINING THE SAFE BED- BREADTH OF FAIRWAY}

Safe breadth of fairway bed is a random variable of normal distribution $[2 ; 6]$. In optimizing sea waterway systems, probabilistic methods have found their application for determining the safe breadth of fairway bed. These are simulation methods and CIRM method (CIRM stands for Sea Traffic Engineering Centre). In the probabilistic model safe breadth of maneouvring water area is a random variable. For the parameter normal distribution is usually assumed, which shows a good conformity with real life (Fig.1). Distribution of distance between extreme points of maneouvring water area and fairway midline can be expressed in the following form [4]:

$$
\begin{aligned}
d_{l j}(y) & =\frac{1}{\delta_{l} \sqrt{2 \Pi}} e^{-\frac{\left(y-m_{l j}\right)^{2}}{2 \delta_{l j}^{2}}} \\
d_{p j}(y) & =\frac{1}{\delta_{p} \sqrt{2 \Pi}} e^{-\frac{\left(y-m_{p j}\right)^{2}}{2 \delta_{p j}^{2}}}
\end{aligned}
$$

$d_{1 j}(y) ; d_{p j}(y)$ - densities of distribution of distances between fairway midline and left-hand and right-hand side boundaries of manoeuvring water area;

$\mathrm{m}_{\mathrm{lj}} ; \delta_{\mathrm{lj}}-$ mean value and standard deviation of distances between fairway midline and left-hand side boundary of manoeuvring water area;

$\mathrm{m}_{\mathrm{pj}} ; \delta_{\mathrm{pj}}-$ mean value and standard deviation of distances between fairway midline and right-hand side boundary of manoeuvring water area;

In simulation methods a simplified method for determining the safe breadth of fairway consists in determining it in function of longitudinal coordinate of fairway axis which, 
in this case, is equivalent to water area axis. Breadth of safe manoeuvring water area in i-th point of fairway or port entrance can be determined for a given series of simulation manoeuvres (series of trials) as follows [4]:

$$
d_{j}(1-\alpha)=\left(y_{l j}+c s_{l j}\right)+\left(y_{p j}+c s_{p j}\right)
$$

where:

$d_{j}(1-\alpha)$ - safe breadth of a fairway in $j$-th point of fairway on the confidence level of 1- $\alpha$;

$\mathrm{y}_{\mathrm{lj}} ; \mathrm{y}_{\mathrm{pj}}$ - mean arithmetic value of maximum distances from ship's point to the left and right to $j$-th point of fairway axis (estimators: $\mathrm{m}_{1}$ and $\mathrm{m}_{\mathrm{p}}$ );

$s_{\mathrm{lj}} ; \mathrm{s}_{\mathrm{pj}}$ - standard deviation of trial series for maximum distances from ship's point to the left and right to $\mathrm{j}$-th point of fairway axis (estimators : $\sigma_{1}$ and $\sigma_{\mathrm{p}}$ );

$c-$ a coefficient depending on an assumed confidence level

(e.g. taken as $c=1,96$ for the confidence level : $1-\alpha=0,95$ ).

Arrangement of a safe manoeuvring water area on a fairway is presented in Fig.1.

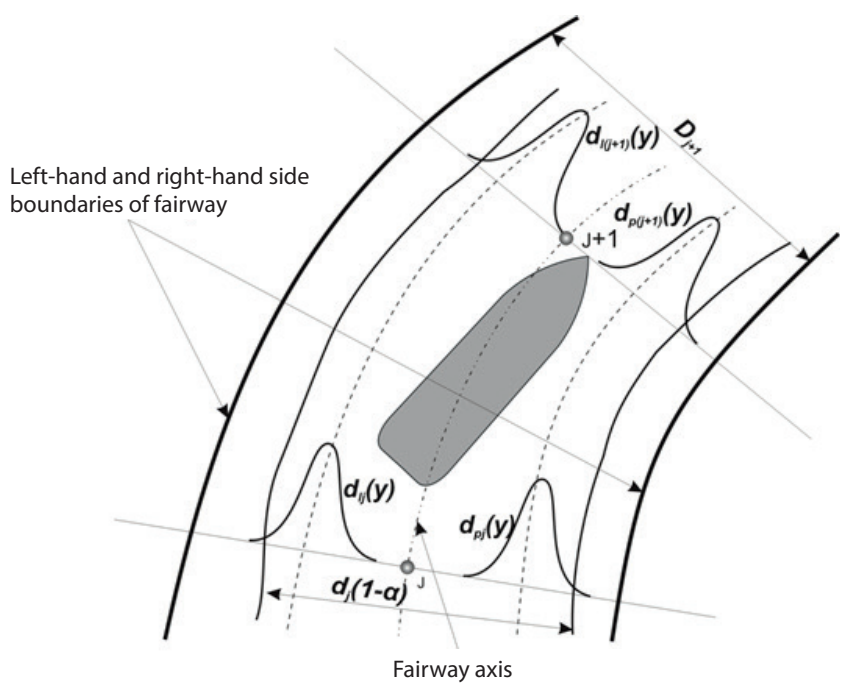

Fig. 1. Arrangement of safe manoeuvring water area on fairway

In the CIRM deterministic-probabilistic method for determining the safe breadth of fairway it was assumed that the standard deviation of maximum distances from ship's point to the left and right to $\mathrm{j}$-th point of fairway axis is approximated by standard deviation of error in directional location of ship's side to the left and right, determined for an appropriate confidence level. The error in directional location of ship's side is determined for a navigation system used by the ship over a given segment of fairway [3]. Values of the error are properly described by normal distribution. It is called a navigational component of safe manoeuvring water area, i.e. :

$$
\begin{gathered}
d_{n p j}(1-\alpha)=c \sigma_{j p} \\
d_{n l j}(1-\alpha)=c \sigma_{j l}
\end{gathered}
$$

Under the above mentioned assumptions the safe breadth of fairway can be determined as follows (Fig. 2) [9]: $d_{j}(1-\alpha)=d_{m j}+d_{n p j}(1-\alpha)+d_{n l j}(1-\alpha)[\mathrm{m}]$

where:

$d_{j}(1-\alpha)$ - safe breadth of manoeuvring water area on the confidence level of (1- $\alpha)$, [m];

$\mathrm{d}_{\mathrm{mj}}$ - manoeuvring component of breadth of safe manoeuvring water area determined by using the deterministic method, [m];

$\mathrm{d}_{\mathrm{npj}}(1-\alpha) ; \mathrm{d}_{\mathrm{nlj}}(1-\alpha)$ - navigational (left and right) components of breadth of safe manoeuvring water area on the confidence level of (1- $\alpha),[\mathrm{m}]$.

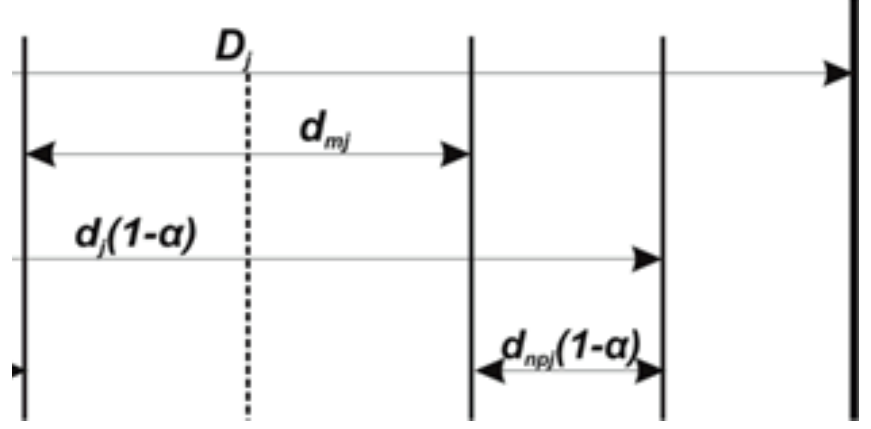

Fig. 2. Safe breadth of fairway on a given confidence level

In both the cases, after taking into account a breadth margin associated with bank effect, the following safety condition for navigation over a given fairway is to be fulfilled:

$$
D_{j} \geq d_{j}(1-\alpha)+d_{r p}+d_{r l}
$$

where:

$d_{r p} ; d_{r l}-$ breadth margin for right and left side of fairway,

In the detail design stage of sea waterways including determination of safe bed-breadth values of fairways the three following methods may be used :

1. The simulation method for determining ship motion in real time by making use of non-autonomous models including navigator as an element [7]. The limitations of the method are:

- $\quad$ possible application to all kinds of waterways except of long (> $3 \mathrm{NM}$ ) straight segments of fairways;

- $\quad$ required application of appropriate maneouvring simulators and software;

- $\quad$ proper experience required from persons making use of the method for simulation research and mathematical modeling;

- a high accuracy of the method which depends on applied simulators, ship models, design of an experimental system and run of processing the obtained results;

- the method is labour - and cost - consuming and requires to carry out long-lasting investigations angaging a large group of navigators (experts).

2. The simulation method for determining ship motion in an accelerated time run by using autonomous models including an element being a model of decision-making navigator [7]. 
The limitations of the method are:

- $\quad$ possible application, presently, to only straight fairways and in some cases to fairway bends (appropriate accuracy);

- $\quad$ proper experience required from persons making use of the method in the area of design of human decisionmaking process and ship motion simulation in accelerated time run;

- the method is labour-consuming in the stage of formulating the simulation model.

Run of such experiment is fast and not labour-consuming.

3. The CIRM deterministic-probabilistic method developed by Sea Traffic Engineering Centre, Maritime University of Szczecin [7].

The limitations of the method are the following :

- $\quad$ possible application to all kinds of waterways;

- a lower accuracy compared with othe simulation methods;

- the method, being empirical, does not require to carry out any experimental investigations.

\section{APPLICATION OF THE DEVELOPED METHODS TO MODERNIZATION OF ŚWINOUJŚCIE-SZCZECIN FAIRWAY}

The modernization of Świnoujście-Szczecin fairway consists in dredging the fairway up to $12,5 \mathrm{~m}$ depth, its appropriate broadening as well as fitting it with navigation systems making safe navigation of to-be-operated ships, possible.

As assumed, the basic navigation systems for ŚwinoujścieSzczecin fairway will be the following:

- a terristic system (optical one) accessible at the visibility up to $2 \mathrm{NM}$;

- $\quad$ a pilotage navigation system (PNS);

whereas an additional system will be :

- a radar system.

The „maximum ships” assumed for the calculations are the following [6]:

- $\quad$ a cruising ship $\left(\mathrm{L}_{\mathrm{c}}=260 \mathrm{~m} ; \mathrm{T}=9,0 \mathrm{~m}\right)$;

- a container carrier $\left(\mathrm{L}_{c}=210 \mathrm{~m} ; \mathrm{T}=11,0 \mathrm{~m}\right)$;

- a bulk carrier $\left(\mathrm{L}_{\mathrm{c}}=195 \mathrm{~m} ; \mathrm{T}=11,0 \mathrm{~m}\right)$;

and , taking into account that the ships do not carry dangerous goods, the confidence level equal to

$$
1-\alpha=0,95
$$

was assumed.

Under such assumptions the objective functions was expressed in the following form:

$$
Z=\min D_{j}
$$

with the constraints:

$$
d_{i j k}(0,95) \leq D_{j}
$$

where:

Z - cost of modernization of Świnoujście-Szczecin fairway (its dredging, broadening, and modernizing the navigation system);

$\mathrm{D}_{\mathrm{j}}$ - accessible bed-breadth of the fairway at 12,5 m depth contour in $\mathrm{j}$-th point of fairway axis;

$\mathrm{d}_{\mathrm{ijk}}$ - safe bed-breadth of the fairway in $\mathrm{j}$-th point of fairway axis for i-th type of „, maximum ship” passing through the fairway in k-th navigation conditions.

Determination of a minimum value of the safe bed-breadth, $\mathrm{d}_{\mathrm{ijk}}(0,95)$, of the fairway was performed in two phases.

In the $1^{\text {st }}$ phase a minimum safe bed- breadth of the fairway on the confidence level of 0,95 was determined for particular segments of Świnoujście-Szczecin fairway between $16^{\text {th }}$ and $67^{\text {th }} \mathrm{km}$ of its length by using the CIRM method. Fig. 3 shows calculation results for the cuiser going from Świnoujście to Szczecin.

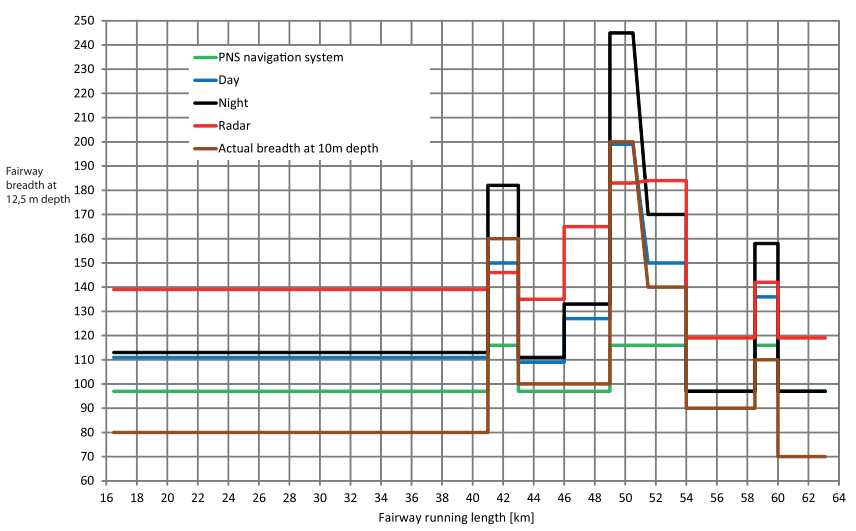

Fig. 3. Safe breadth of Świnoujście-Szczecin fairway for the cruiser going from Swinoujście to Szczecin, calculated for the existing navigation marking on the confidence level of 0,95

On the basis of calculation results reached with the use of CIRM method, final values of bed-breadth of the fairway were obtained for its straight segments as well as parameters of their navigation systems.

In the $2^{\text {nd }}$ phase, the simulation method of ship motion in real time was applied to calculate safe breadth values of fairway bends. The research was performed by using a Konsberg Maritime AS Polaris multi-bridge maneouvring simulator fitted with 3D-projection visualization. By means of the simulator, 3D geometrical models of the considered fairway bends as well as simulation models of the examined „maximum ships” were formed, assuming safe isobates for 12,5 $\mathrm{m}$ depth determined by using CIRM method.

The investigations were carried out in series for two directions of wind of $10 \mathrm{~m} / \mathrm{s}$ speed and sea current of $0,7 \mathrm{kn}$ speed. Particular simulation passages in series, of $12 \div 15$ in number, were executed by different pilots. On the basis of the values of safe bed-breadth of the fairway, calculated on the 0,95 confidence level, accessible navigation water areas for Świnoujście-Szczecin fairway of 12,5 $\mathrm{m}$ in depth and parameters of navigation systems for these areas were determined. 
Exemplary results of the $2^{\text {nd }}$ phase investigations for the Święta bend $(58,5 \mathrm{~km} \div 60,0 \mathrm{~km})$ are presented in Fig. 4 and 5 .

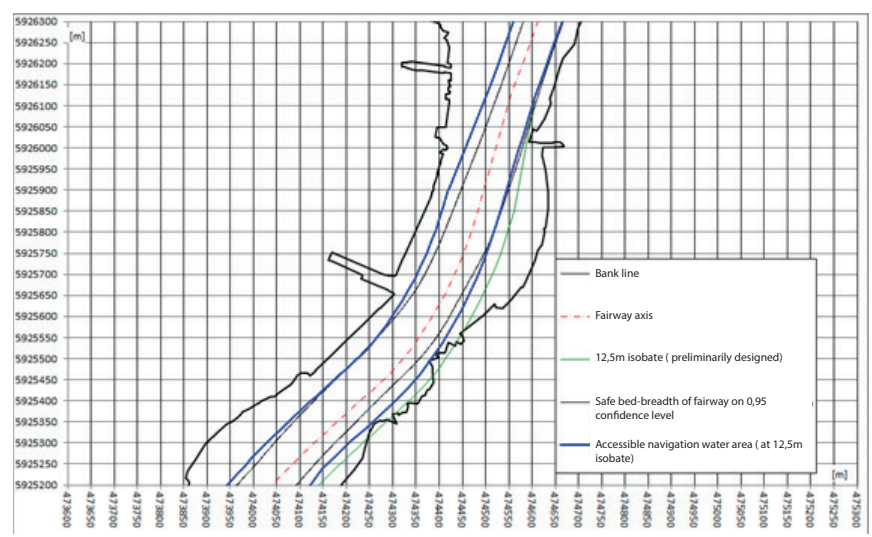

Fig. 4. Swięta bend. Safe bed-breadth values of the fairway, determined on 0,95 confidence level, and the accessible navigation water area (north part)

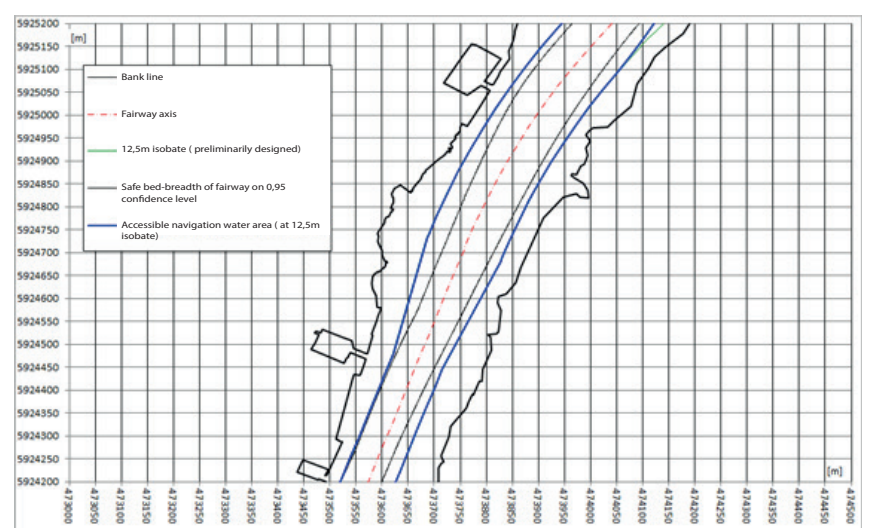

Fig. 5. Swieta bend. Safe bed-breadth values of the fairway, determined on 0,95 confidence level, and the accessible navigation water area (south part)

\section{CONCLUSIONS}

In this paper has been described the optimization method for sea waterway systems, based on three probabilistic methods for determining safe values of fairway bed-breadth. Thes are the following:

- the simulation method for determining ship motion in real time by making use of non-autonomous models;

- the simulation method for determining ship motion in accelerated run of time;

- the CIRM deterministic probabilistic method.

The developed optimization method may be applied in the detail design stage of waterway system; however, taking into account accuracy and cost consumption of the particular methods for determining safe values of fairway bed-breadth, the following sequence of their application has been proposed:

Phase 1. Optimization of parameters of waterway system, carried out by means of CIRM method to reach the following:

- determination of optimum values of parameters of straight segments of fairways and their navigation systems;

- preliminary determination of parameters of complex maneouvring water areas of fairways, to be used in Phase 2 .
Phase 2. Optimization of parameters of complex manoeuvring water areas of wateway system, carried out by means of simulation methods of ship motion in real time to reach the following:

- determination of optimum values of parameters of complex manoeuvring water areas of fairways and their navigation systems.

The above described two-phase optimization method of sea waterways was applied to the modernization project of Świnoujście-Szczecin fairway. The modernization consisted in dredging the fairway from $10,5 \mathrm{~m}$ up to $12,5 \mathrm{~m}$ depth, that forced:

- to change conditions of safe operation of ships sailing along the fairway;

- to determine optimum parameters of the fairway and its navigation systems.

\section{BIBLIOGRAPHY}

1. GucmaS.(Editor):„Navigationalanalysis of modernization project of Świnoujście-Szczecin fairway (dredging up to 12,5m depth)" (in Polish). Scientific research ordered by Europrojekt Gdańsk S.A.; project investor: Szczecin Maritime Administration (Urząd Morski w Szczecinie). Maritime University of Szczecin, Szczecin 2014

2. Gucma L.: „Modeling of factors for risk of collision between floating units and port facility structures" (in Polish). (Studies 44), Maritime University of Szczecin, Szczecin 2005

3. Gucma S.: „Pilotage navigation” (in Polish). Publisher: Foundation for Promotion of Shipbuilding Industry and Maritime Economy (Fundacja Promocji Przemysłu Okrętowego i Gospodarki Morskiej) , ISBN 83-919488-54. Gdańsk 2004.

4. Gucma S.: The width of a fairway - comparison of models". Journal of Konbin, No 1(13)2010, ISSN 1895-8281. Warszawa 2010.

5. Gucma S.: "Optimization of sea waterway system parameters in marine traffic engineering". Journal of Konbin, No 2(26)2013, ISSN 1895-8281. Warszawa 2013.

6. Gucma S.: "Systems approach to sea waterways". Scientific Bulletins of Maritime University of Szczecin, No 38 (110) , 2014, ISSN 1733-8670. Szczecin 2014. 
7. Gucma S., Gucma L., Zalewski P. : „Simulation research methods in sea traffic engineering" (in Polish). A monograph edited by Gucma S. ; ; Publishing House of Maritime University of Szczecin (Wydawnictwo Naukowe Akademii Morskiej w Szczecinie), ISBN 978-83-8990129-3, Szczecin 2008.

8. Gucma S., Ślączka W., Zalewski P. : „Parameters of fairways and navigation systems determined with the use of safe navigation criteria" (in Polish). A monograph edited by Gucma S. ; Publishing House of Maritime University of Szczecin (Wydawnictwo Naukowe Akademii Morskiej w Szczecinie), ISBN 978-83-89901-82-8. Szczecin 2013.

9. Gucma S., Zalewski P.: "Deterministic-probabilistic method of waterway design parameters determination". Annual of Navigation, No 19/2012, part 2., ISSN 16408632. Gdynia 2012.

\section{CONTACT WITH AUTHOR}

\author{
Stanisław Gucma \\ s.gucma@am.szczecin.pl \\ Wojciech Ślączka \\ w.slaczka@am.szczecin.pl \\ Maritime University of Szczecin \\ Wały Chrobrego 1-2 Str. \\ 70-500 Szczecin \\ POLAND
}

